\title{
CORRECTION
}

\section{Correction to: Association between anti-seizure medication and outcomes in infants}

Elizabeth K. Sewell (D), Shannon E. G. Hamrick, Ravi M. Patel (D, Monica Bennett, Veeral N. Tolia and Kaashif A. Ahmad (D)

(c) The Author(s), under exclusive licence to Springer Nature America, Inc. 2021

Journal of Perinatology (2022) 42:421; https://doi.org/10.1038/s41372-021-01285-2

Correction to: Journal of Perinatology https://doi.org/10.1038/ s41372-021-01240-1, published online 20 October 2021
In the original version of the paper was missing a table in the Supplementary information. This has now been added. The original article has been corrected. 